\title{
THE ATTITUDE OF THE ELDERLY TOWARDS ROBOT ASSISTED DAILY LIFE ACTIVITIES
}

\author{
1"Tianyang Huang \\ Doctoral Program in Design, College of Design, National Taipei University of Technology, Guangdong \\ Ocean University, Taipei, Taiwan
}

\section{${ }^{2}$ Chiwu Huang}

Department of Industrial Design, College of Design, National Taipei University of Technology, Taipei, Taiwan

\begin{abstract}
This article attempted to understand the attitude of the elderly to the use of robots to assist in activities of daily living (ADLs). The study first learned about major items of ADLs of elderly people living independently through one-on-one interviews, and then let the seniors fill in the attitude questionnaire and the acceptance questionnaire after watching the robot video. The results showed that the mean scores of seniors in the attitude questionnaire were greater than 3 (3 stands for neutral), and they highly accept the use of robots to assist ADLs such as reminding people to carry items, reminding to take medicine, reminding important things, reminding the location of items, cleaning and looking for things. The results suggested that seniors hold an open attitude towards the use of robot assistance. The research results can provide an understanding on the user's assistance needs and attitudes, as well as reference for the design of the robot, especially the functional design, ultimately improving the ability of the elderly to live independently and improve their quality of life.
\end{abstract}

KEYWORDS: home activities; older adults; acceptance; TAM; robotics;

Article Received: 10 August 2020, Revised: 25 October 2020, Accepted: 18 November 2020

\section{INTRODUCTION}

\section{Ageing}

The world population is rapidly ageing. According to the United Nations Department of Economic and Social Affairs (United Nations Department of Economic and Social Affairs, 2015), the proportion of the population of 60 years and older will increase from $12 \%$ in 2015 to $25 \%$ in 2050, which means one in four people is an elderly person then. In Europe, the population over the age of 65 will increase from 101 million in 1995 to 173 million in 2050 (United Nations Department of Economic and Social Affairs, 2007). The population of 60 years old and above in China will increase from $12.4 \%$ in 2010 to 28\% in 2040 (United Nations Department of Economic and Social Affairs,2013).

\section{Seniors Living Independently}

In the context of population aging, older people prefer to live independent lives in familiar homes rather than spending their old age in nursing homes (Broekens, Heerink, \& Rosendal, 2009; Groves \& Wilson, 1993). According to the statistics from the World Population Ageing 2017 (United Nations,
2017), in the period circa 2010 , about $40 \%$ of people at the age of 60 or above live independently (alone or with a spouse only), and this figure is as high as 93.4\% in the Netherlands. The report also shows that the assessment of the overall trend of elderly people living independently is challenging because of the lack of all relevant data, but overall, the elderly are more likely to live independently. Because the proportion of elderly living independently circa 1990 was $24 \%$, and it rose to $37 \%$ circa 2010 .

Maintaining independence is the main goal of the elderly (Gitlin, 2003; Lawton, 1990). To achieve this goal, the elderly must perform many activities on their own to meet their daily needs and ultimately achieve independence. The activities of daily living (ADLs) (Rogers, Meyer, Walker, \& Fisk, 1998) include eating, dressing, etc. (Lawton, 1990) , as well as personal health care activities such as drug reminders (Kelly, Fausset, Rogers, \& Fisk, 2014). However, in daily life, there are some ADLs that older people are reluctant to do or even do not want to do (Hoefman, Meulenkamp, \& De Jong, 2017). In addition, with the gradual increase in age of these 
independent living seniors, their memory and cognitive ability will gradually decline (Hedden \& Gabrieli, 2004; Moro, Lin, Nejat, \& Mihailidis, 2019). Therefore, they need some assistance when they live independently. In recent years, with the development of robotics, it may be beneficial to use robots to assist seniors in performing ADLs (Fausset, Kelly, Rogers, \& Fisk, 2011), and robots are attracting attention as a potential solution to the problem of ageing (Abdi, Al-Hindawi, $\mathrm{Ng}, \&$ Vizcaychipi, 2018; Begum, Huq, Wang, \& Mihailidis, 2015; Garcia-Soler et al., 2018; Lukasik, Tobis, Wieczorowska-Tobis, \& Suwalska, 2018; Whelan et al., 2018).

\section{Acceptance of Using Robots to Assist ADLs}

Some studies (Beer et al., 2012; Broekens et al., 2009; Chen \& Chan, 2011; Gallego-Perez, Lohse, \& Evers, 2013; Klamer \& Allouch, 2010; A. S. Melenhorst, Rogers, \& Bouwhuis, 2006; Smarr et al., 2012; Takayama, Ju, \& Nass, 2008) explored using robots to assist ADLs. However, most of the studies were conducted on the same user group. For example, Beer et al. (2012) conducted a questionnaire survey on 21 independent living elderly people, and found that the elderly preferred robot assistance. Klamer and Allouch (2010) investigated how senior citizen use the transformable robot Nabaztag in their home environment for 10 days, in order to understand whether people can build relationships with Nabaztag. They found that the health of older people did not improve significantly. Gallego-Perez et al. (2013) studied the emotional and psychological support provided by robots. If the benefits of using technology are obvious, then elderly people are willing to accept technical assistance (Melenhorst et al., 2006).

Some studies also explored the acceptance level of different user groups. For example, $\mathrm{Xu}, \mathrm{Ng}$, Tan, and Huang (2015) studied the needs and attitudes towards robot assistance among three generations of 10 families, and found that the users of all ages in the families wanted robots to help with housework and they cared the most about the pragmatic use and efficiency. Wang, Sudhama, Begum, Huq, and Mihailidis (2017) used semi-structured interview to study the use of robots in assisting ADLs for 10 pairs of participants consisting of elderly patients with mild to moderate Alzheimer's disease and their caregivers. They found that $\mathrm{AD}$ patients felt that robots can help with ADLs, but they did not want robot assistance, and their caregivers were more open to robots. However, despite that these researches on robots to assist ADLs were conducted in different user groups, the elderly participants in these researches are not users of independent living.

Most current research on robot-assisted acceptance is mainly conducted in the same user group (Broekens et al., 2009; Chen \& Chan, 2011; Klamer \& Allouch, 2010; Smarr et al., 2012), especially for elderly users; while little is known about the acceptance of robot-assisted in ADLs of both seniors and future seniors (college students). In the context of rapid population ageing, today's seniors are our focus of attention, as they are potential users and beneficiaries of assistive robot development in recent years. However, according to the reported trend (United Nations, 2017), perhaps the problem of ageing will be more serious 40 years and 50 years later. Hence, today's college students will be the potential users of the future of robots and also deserve attention in research. Understanding of their attitudes towards using robots to assist ADLs could provide reference for the development and design of robots that are currently attracting attention. At the same time, the future seniors (college students) can learn about robot assistants through this study, so that they might have higher level of acceptance towards robots when they are old.

\section{Acceptance Theory Model}

Acceptability is a key factor for users to accept or reject new technologies (Dillon, 2001), and the ease of use and usefulness of new technologies are important factors influencing people's acceptance. This has been verified in the original Technology Acceptance Model (TAM) (Davis, 1989) and Almere (Marcel Heerink, Krose, Evers, \& Wielinga, 2009; Heerink, Krose, Evers, \& Wielinga, 2010). Venkatesh, Morris, Davis, and Davis (2003) found that the technology acceptance model can predict the user's acceptance of new technologies. The original TAM was developed based on Theory of Reasoned Action (TRA) to explain and predict user acceptance of new technologies. TAM states that Perceived Ease of Use

(PEOU) and Perceived Usefulness (PU) are the main factors affecting the seniors' intention to use (Davis, 1989; Heerink et al., 2010). Broadbent et al. (2012) suggested that the seniors' intention to use robots can be predicted by Perceived Ease of Use. The Almere model (Heerink et al., 2010) allows users interacting with the robot to find PEOU and PU to affect the users' intention to use.

The Almere model indicates that Attitude towards Technology also significantly affects users' intention to use (Heerink et al., 2010). Attitude is an important 
predictor of robot acceptance. Attitude is a very broad concept and it is also a factor that changes frequently (Marcel Heerink et al., 2009). Attitude can be understood as a judgment of users on the value of a given target (Eagly \& Chaiken, 1993). It has both emotional and cognitive components (Adams, Nelson, \& Todd, 1992; Crites Jr, Fabrigar, $\&$ Petty, 1994). In the two categories of affective attitude and cognitive attitude, the cognitive attitude also affects the affective attitude (Yang \& Yoo, 2004). In the Almere model, attitudes refer to positive or negative feelings about the application of technology. Research indicates that users' positive or negative attitudes will affect their interaction with the robot (Heerink et al., 2010; Nomura, Kanda, Suzuki, \& Kato, 2008) and also affect users' acceptance of robots (Broadbent, Stafford, \& MacDonald, 2009; Young, Hawkins, Sharlin, \& Igarashi, 2009). It has a significant impact on the intention of use and is a key factor affecting acceptance (Marcel Heerink et al., 2009; Heerink et al., 2010; Yang \& Yoo, 2004; Young et al., 2009). As some studies (Louie, Mccoll, \& Nejat, 2014; Stafford, MacDonald, Jayawardena, Wegner, \& Broadbent, 2014) pointed out that conducting attitude research on robotics is a necessary condition to guide the development of new technologies. Hence, users' attitude toward robot assistant is worth discussion.

\section{Purposes of Research}

As discussed above, there is little research on the attitudes of robots to assist ADLs among different user groups, especially between today's seniors and future seniors, They are all potential users of the robot. Therefore, this study used quantitative methods to explore the attitude of the today's seniors and future seniors (college students) towards the use of robots to assist ADLs. The study purposes are as follows:

1. To understand the main activities of daily living items for old people living independently.

2. To understand the attitudes of seniors to the use of robots to assist the aged in their daily lives.

3. To determine the level of acceptance of robot assistance in various activities of seniors.

\section{Novelty of the study}

The study has the following novel features. First, two groups of participants were included: future seniors (college students) and current seniors, which are different from the exploration of a single group in current research (Beer et al., 2012; Gallego-Perez et al., 2013), and it helps to understand the acceptance attitude of elderly users, and may provide reference for robot development design in recent years and in the future. Second, the research report by the United Nations (2017) pointed out the proportion of elderly people living independently is high and may be forming a growing trend. Therefore, this study is aimed at users' attitudes toward using robots to assist their ADLs in their homes, which is different from previous research on related issues in nursing home institutions (Campbell, 2011). Third, since most of the participants in previous studies were the elderly in Europe (Gnambs \& Appel, 2019; Jaschinski \& Ben Allouch, 2019; Łukasik et al., 2018; Rantanen, Lehto, Vuorinen, \& Coco, 2018; Wu, Fassert, \& Rigaud, 2012; Zsiga et al., 2013) and the U.S. (Beer et al., 2017; Mitzner, Chen, Kemp, \& Rogers, 2014; Smarr et al., 2014), while the participants in this study were all from China in the Asian region, so this study will also increase people's understanding of other regions. Fourth, the research used a combination of qualitative and quantitative methods, which differs from previous studies using a single method (Ezer, Fisk, \& Rogers, 2009; Takayama et al., 2008) and will make the results more comprehensive and considerate.

\section{METHODS}

\section{Participants}

The participants included 36 elderly people living independently ( 7 of them participated in the first-phase one-on-one interview) and 29 future elderly (college students). The average age of the 7 interview participants was 75.71 (SD $=8.674$, Range $=65-88$ years old, 4 females). The average age of the 29 elderly participants in the survey was 71.1 ( $\mathrm{SD}=5.115$, Range $=61-81$ years old, male: 12 , female:17), the average age of 29 future elderly (college students) surveyed was 21.17 ( $\mathrm{SD}=0.658$, Range $=20-22$ years old, 17 males, and 12 females). The questionnaire items on the participants' experience in robot use revealed that 21 elderly $(72.4 \%)$ indicated no experience in robot use, and 6 elderly $(20.7 \%)$ indicated that they had primary experience (having seen robots in exhibition hall, on TV or in newspapers), and 2 elderly(6.9\%) had intermediate experience (who had used robots). None of the seniors had advanced experience (developing and designing robot hardware or software). The proportion of the future elderly (college students) who indicated no experience, primary, intermediate and advanced robotic experience were $10 \%$ (3 people), 56.7\% (17 people), $30 \%$ (9 people), and $0 \%$ (0 person) respectively. All senior participants received a supermarket shopping 
coupon worth NTD 100 as compensation for participation in the survey.

\section{Interview}

The purpose of the interview was to understand the main items of ADLs of the elderly living independently. The interview was conducted to 7 seniors recruited by the Yongjian Evergreen Promotion Association in Taipei, Taiwan. The interview was conducted one-on-one. The interview duration was 81 minutes and 06 seconds. The interviews mainly focused on the following five questions: 1) What do you often do at home? 2) Can you describe the daily activities of your whole day from getting up in the morning to sleeping in the evening? 3) What kind of activities (or things) do you think are difficult to accomplish by yourself? 4) What activities (or things) do you have in your daily life that you want to have someone else (or something else) to help you with? 5) what kind of activities do you think need to be assisted in your daily life in the future?

\section{Video}

The online public video Buddy robot (Buddy, 2018) demonstrates the interactive scene of robot-assisted ADLs, which is in line with the theme of this research. Buddy was designed and developed by the French company, Blue Frog Robotics. It has a head display and a body base, with daily life functions of wake-up service, answering calls, controlling home appliances, playing music, reminding the elderly to take medicine, event reminders and others, and can provide some family assistance for the elderly. Users can interact with Buddy by voice, face recognition and other technologies. Before the participants watched the video, the researchers turned the video subtitles into Chinese, so that participants can have a clearer understanding of the video content and the subject of this research.

\section{Questionnaire \\ Attitude Questionnaire}

Both TAM (Davis, 1989) and Almere (Heerink et al., 2010) indicate that Ease of Use and Usefulness are the main factors affecting users' intention to use and also important predictors of predicting users' acceptance of technology. At the same time, Attitude significantly affects the users' intention to use (Louie, McColl, \& Nejat, 2014; Stafford et al., 2014). Therefore, the theoretical framework of this research was based on the Technology Acceptance Model and Almere Model. The attitude questionnaire of this study was based on three constructs: PEOU (6 items), PU (6 items) and ATT (3 items) with a total of 15 items, as shown in Table
1. The Likert five-point scale was used for measurement ( 1 as totally disagree, 3 as uncertain, 5 as totally agree). The questionnaire was filled out by participants after watching the video. This study then calculated the Cronbach's alpha of the questionnaire (Santos, 1999). The internal consistency reliability of the ATT questionnaire filled by the elderly was higher, with the $\alpha$ value of .769 , and the internal consistency reliability of the ATT questionnaire filled by the future seniors (college students) was also high, with the $\alpha$ value of .877 , which both exceeded 0.7 , indicating good reliability.

\section{Activities of Daily Living (ADLs) Acceptance Questionnaire}

According to the interview in the first phase, this research analyzed the results and summarized 32 ADLs items of independent living adults. Based on these ADLs, this study then developed a Daily Living Activities (ADLs) Acceptance Questionnaire, as in Table 2. This questionnaire was filled out by the participants after watching the robot video. The questionnaire was measured with the Likert five-point scale ( 1 as totally disagree, 3 as uncertain, 5 as totally agree). The reliability of the questionnaire was calculated by Cronbach's Alpha (Santos, 1999). The score of the questionnaires filled out by the elderly was 0.907 , and the score of the questionnaires filled out by college students was 0.858 , both exceeding 0.7 and indicating a high reliability.

\section{Procedure}

The research includes two stages: interview and questionnaire survey. First, based on the one-on-one interview in the first phase, the ADLs of the elderly living independently were obtained with a total of 32 items, which were used as the basis for the acceptance questionnaire in the second phase. Then, the participants were asked to sign the informed consent before viewing the robot related video. Finally, the participants were asked to anonymously fill out the acceptance questionnaire and the acceptance questionnaire on robots to assist ADLs after watching the robot video. The questionnaire in the second phase was conducted in Taipei and Zhanjiang.

\section{DATA COLLECTION AND ANALYSIS}

This study recruited seniors from the Yongjian Evergreen Promotion Association in Taipei, Taiwan, and future seniors (college students) at Guangdong Ocean University in Zhanjiang, China. One-on-one interview and paper questionnaire survey was conducted in May-June 2019. 
The interview recording documents were converted into texts by using the online transcription platform (https://www.iflyrec.com/) of the professional transcription company iFLYTEK. Then the researchers checked the transcription results and the recorded contents one by one, and corrected them. The basic statistical methods were used to analyze the questionnaire data and calculate descriptive statistics, including mean, maximum, minimum, standard deviation, etc. Mann-Whitney $U$ test statistical analysis method was also used. It should be noted that if the mean score in this study is equal to 3 , it means an uncertain and neutral attitude; if it is below 3 , it means a passive and negative attitude; if it is above 3 , it means an active and positive attitude.

\section{Results \\ Interview}

After the recruitment of seniors living independently by the Yongjian Evergreen Promotion Association in Taipei, the researchers conducted one-on-one interviews with them in the office of Yongjian Evergreen Promotion Association in Taipei. There were 7 participants. The verbatim analysis of the interview results found that respondents would consider age, current physical condition, and uncertain factors such as possible future deterioration of the body when considering the assistance of ADLs, such as: "Now I'm still young and take care of everything at home by myself. When I get older or have some physical pain, it is more convenient for someone to accompany me at home or help me when I cook or go out to buy something (Interviewer 3, Female, 65 years old), "When older people go out to do something, they need someone to accompany them, support them with hands, or remind them of taking medicine or the location of something. When I am sick, I hope someone will accompany me and do some housework, such as cleaning, etc." (Interviewer 4, Female, 66 years old), and "It is very important to take medicine for someone like our age. It is very important to give medication reminders and reminder for location of medicines, because I don't remember well, and tend to forget" (Interviewer 7, Male, 81 years old). Therefore, when we are reviewing the results of interviews, in addition to considering the ADLs that older people may need or want assistance now, we should also consider ADLs of higher frequency that the elderly do not need assistance at present, but will need assistance in the future, such as cooking, laundry, reminding to take medicine, etc. Moreover, the ADLs performed more by elderly people but were not mentioned have been sorted out, including watching $\mathrm{TV}$, preparing breakfast, etc. This study formed a total of 32 items of ADLs for seniors through one-on-one interviews with 7 elderly people living independently, as shown in Table 2. These ADLs were used as the basis for preparing the follow-up questionnaire.

\section{Questionnaire}

\section{Attitude questionnaire}

Table 1 shows descriptive statistics on today's seniors and future seniors (college students) in the Attitude Questionnaire: minimum, maximum, mean and standard deviation. The results showed the mean scores of seniors and future seniors (college students) in all items of the attitude questionnaire were more than 3 , among which, the mean score of future seniors (college students) on the seven items exceeded 4, and the mean score of the elderly on 5 items exceeded 4 . The results indicated that the attitude of future seniors (college students) and senior participants in using robots to assist daily life was positive. It is worth noting that the mean scores of future seniors (college students) in the six question items of the Perceived Usefulness construct were all greater than 4 , and the mean score of each item exceeded the mean score of the senior participants. This indicated that the future seniors were more positive about the PU of the robot. In the items where the mean scores of the seniors were higher than 4, the scores of the seniors were higher than the scores of the future seniors in the following items: "Using robot assistance makes my job easier", "It's good to make use of the robot in my daily life" and "The robot assistance in ADLs would make my life more interesting". The Mann-Whitney U test was performed on the questionnaire data of the future seniors (college students) and seniors. The analysis found that among all the items in the questionnaire, there was a significant difference between the mean scores of the items "It is easy to learn how to use a robot" and "It is easy for me to become skillful in operating the robot" $(p<0.01)$, which was statistically significant. The mean scores of the remaining 13 items were not statistically significantly different, but both seniors and future seniors (college students) expressed an open attitude towards the use of robots to assist in everyday life. Comparatively, the attitude of future seniors (college students) was more positive, as they thought it is easy to learn how to use a robot, and easy for them to become skillful in operating the robot too.

The acceptance questionnaire of activities of daily living (ADLs) 
Table 2 shows that robot assistance was used in 32 ADLs. Most of the elderly and future seniors (college students) showed a more positive and open attitude. For the elderly participants, except for the mean score of the bathing was less than 3, the remaining 31 items of ADLs all had a mean score of over 3 , and the mean score was 4 or more for the 7 items of ADLs of finding things, reminding important things, cleaning, reminding the location of items, emergency call, reminding them to take medicine and reminding them carrying things. For future seniors (college students), the mean score was less than 3 for bathing and playing mahjong. The mean score for eating was 3 , and the mean scores of the remaining 29 ADLs were all higher than 3, and the mean scores of 15 activities including preparing breakfast, using computer, reminding to carry items, reminding to take medicine, emergency call, reminding of item location, cleaning, reminding important things, preparing lessons, looking for things, washing and drying beddings, inspection and maintenance of home appliances, laundry, clothes drying and photo archiving were all higher than 4 . The study has also shown that in the ADLs with a mean score between 3 and 4, the open attitude of older people in using robot assistance for green grocery shopping, walking, dancing, playing Tai Chi, cooking and shopping activities were higher than that of the future seniors (college students).

According to the Mann-Whitney $\mathrm{U}$ test analysis, there was a significant difference in the mean score $(p<0.05)$ with statistical significance in the acceptance of robot assistance in 14 ADLs between future seniors (college students) and seniors of all the 32 ADLs, as shown in Table 2. In addition, it is worth noting that in the activities of walking, playing Tai Chi and bathing, the mean score of the elderly was significantly higher than that of the future seniors.

\section{DISCUSSION}

In recent years, robotics has become a potential solution to the problems related to population ageing and has received widespread attention (Garcia-Soler et al., 2018; Marcel Heerink, Krose, Evers, \& Wielinga, 2006; Marcel Heerink, Kröse, Evers, \& Wielinga, 2008; Robinson, MacDonald, \& Broadbent, 2014; Whelan et al., 2018). This study used qualitative interviews and quantitative questionnaires to try to understand the attitudes of the elderly and future seniors (college students) toward using robot to assist seniors' ADLs, and to determine at the same time their acceptance of using robot to assist in the daily lives of senior citizen living independently. The research has shown that both future seniors (college students) and current seniors had a mean score of more than 3 in all items in the attitude questionnaire, and the mean scores in the acceptance the questionnaire were mostly more than 3. The study shows that seniors expressed a positive attitude towards robot assistance in daily life, and most had a relatively open acceptance of the use of robot assistance in daily life. The research findings help increase understanding of using robots to assist the ADLs of older people living independently, also help understand the attitudes of seniors to the use of robot to assist ADLs, and the acceptance of the use of robot to assist each item of ADLs. These findings will provide a reference to the development of robots, in particular, the functional design, so as to improve the ability of old people to live independently and improve the quality of life of the elderly.

The elderly may differ greatly from young people in terms of technical acceptance. The elderly are less likely to master new technologies than younger people, such as computers (Stafford et al., 2014), and they may be less willing to adopt new technologies (Charness \& Boot, 2009). However, in our study, the mean scores of future seniors and seniors in the 15 items of the attitude questionnaire exceeded 3, indicating that both groups of participants held an open attitude towards the robots in terms of the construct of Perceived Usefulness, the construct of ATT and the construct or PEOU, and they maintained a positive attitude toward robots to assist seniors. In the perception of the construct of Perceived Usefulness, the mean scores of future seniors were higher than 4 , and their attitudes were more positive than those of the older people. Of course, from this point, we can tell the acceptance of robotics by seniors is indeed lower than that of future seniors.

Robots must meet the needs of users (Broadbent et al., 2009; Forlizzi, DiSalvo, \& Gemperle, 2004). User needs may be related to their PEOU of the robot, which is one of the important factors affecting the acceptance of new technologies (Ezer et al., 2009). This study found that the college students' mean scores of all items in the construct of Perceived Usefulness in the questionnaire were more than 4 , and the mean score of the seniors in the three items of the construct of Perceived Usefulness also exceeded 4, and the mean scores of the remaining 3 items were also nearly 4 . This indicates that both groups of participants showed a more positive attitude in the construct of PU. In the item of PEOU 
for "It is easy to learn how to use a robot" and "It is easy for me to become skillful in operating the robot", there was a significant difference in the mean score given by the future seniors and senior participants. The study showed that the mean scores of future seniors were higher than those of the elderly, which indicates it is easier for future seniors to learn to use robots and have skilled machine operations than older people, so the college students' attitudes were positive.

Through interviews, this study obtained 32 items of ADLs for elderly people living independently. Overall, this study found that both groups of participants, future seniors (college students) and seniors, showed a more optimistic attitude in the acceptance of using robot to assist in these 32 ADLs, and the mean score of most ADLs was more than 3, and the mean scores of both groups of participants for such items as reminding to carry items, reminding to take medicine, reminding important things, reminding the location of items, cleaning and tidying and looking for something, which indicated that the two groups of participants agreed with the assistance needs of in such ADLs that may cause inconvenience due to ageing, memory loss and other physical deterioration, and were thus more willing to accept external assistance. In addition, the mean score of the two groups of participants in the item of emergency call was also 4 or more, which may be due to such factors as the safety of the elderly.

This research also found that there was a significant difference in the mean score of bathing activity between today's seniors and future seniors (college students) $(\mathrm{p}<0.05)$, but the mean scores given by both groups were below 3 , indicating that they took a negative, unacceptable attitude toward the use of robot assistance in such private personal activities as taking a bath. The mean scores of older people to use robot assistance in 31 ADLs other than bathing were all above 3, indicating that they were holding a positive attitude. In addition, since green grocery shopping, walking, dancing, playing Tai Chi, cooking and shopping are the daily activities of the elderly living independently and are their actual needs, they may feel inconvenient in carrying out these ADLs or convenient by have external assistance, so their mean scores in using robot assistance in these ADLs were higher than future seniors (college students), indicating that they held an opener acceptance of robot assistance in these activities than that of future seniors (college students). The difference between the current seniors and the college students (future older people) suggests that when appropriate, it is necessary to take into account potential users such as college students in the process of developing new technologies for robots to ensure the acceptance of potential users and ultimately improve the acceptance of robot assistance in the future.

This research has some limitations. First, the participants were only participants in Taiwan and China, confined to China in Asia, which limits the general applicability of research results. In the future, trying the intercontinental comparison or comparison between more regions should have different findings. Of course, this should be an interesting and challenging topic. Secondly, the future elderly in this study were limited to the current college students, not including young people of other age groups, which may influence the comprehensiveness of the results. In subsequent studies, we should include young people of the remaining age groups. Also, the sample size was small. Future research could 1 increase the number of research samples. Although in the previous qualitative research (Wu et al., 2012; Zsiga et al., 2018), there were also many studies of small size samples that have been made meaningful findings, the research with large samples can increase the accuracy of the research results to a certain extent. Finally, this study only used video demonstrations in our study without any real robot demonstration, which may limit some users' understanding for robot assistance. Future research should try to use real robots to interact with participants to enrich the user's experience perception to obtain some interesting findings.

\section{CONCLUSION}

Robots have become a potential solution to the problems associated with ageing and has got the attention (Garcia-Soler et al., 2018; Robinson et al., 2014; Whelan et al., 2018). This research attempted to understand the attitude of the elderly to use of robots to assist in ADLs. The study first learned about 32 major items of ADLs of elderly people living independently through one-on-one interviews, and then let the seniors fill in the attitude questionnaire and the acceptance questionnaire after watching the robot video. The interview results showed that for the 32 ADLs items that seniors may need assistance, the results of the questionnaire showed the mean scores of the today's seniors and future seniors (college students) in the attitude questionnaire were more than 3 , of which, the mean scores of future seniors of the seven items were more than 4, and the mean scores of the elderly 
participants of the five items exceeded 4. This study also showed that the mean scores of the elderly to use robot to assist ADLs were greater than 3 except for bathing, while 7 items of ADLs including looking for things, reminding important things, cleaning, reminding the location of items, emergency call, reminding to take medicine and reminding of carrying items got a mean score of 4 or more. The future seniors (college students) only had a mean score of less than 3 for bathing and playing mahjong. The mean scores of 15 activities were all greater than 4 , including preparing breakfast, using computer, reminding to carry items, reminding to take medicine, emergency call, reminding item location, cleaning, important things reminder, preparing lessons, looking for things, Washing and drying beddings, inspection and maintenance of home appliances, laundry, drying clothes and photo archiving. This study has shown that both the seniors were open to robot assistance. Although there were certain differences in the degree of acceptance of robot-assisted for different activities of daily living, and the acceptance of robot-assisted was high for such activities of daily living as reminding to carry items, reminding to take medicine, reminding important things, reminding the location of items, cleaning and looking for things, and there was a negative attitude towards the use of robot assistance in bathing, most of them were willing to accept and took a positive attitude. The findings of this research can provide an understanding of the attitudes of the today's seniors and future seniors to robot assistance ADLs and can provide a reference for robot design, especially functional design, so as to promote the development of robots that meet user needs, and ultimately improve the quality of life of elderly users.

\section{ACKNOWLEDGMENTS}

We would like to express our gratitude to the staff of the Yongjian Evergreen Promotion Association of Taipei for their selfless assistance in this study, as well as to all participants.

\section{CONFLICT OF INTERESTS}

All authors confirmed that there is no conflict of interest.

\section{REFERENCES}

- Abdi, J., Al-Hindawi, A., Ng, T., \& Vizcaychipi, M. P. (2018). Scoping review on the use of socially assistive robot technology in elderly $\begin{array}{llll}\text { care. } & \text { Bmj Open, } & \text { 8(2), } 20 .\end{array}$ doi:10.1136/bmjopen-2017-018815

- Adams, D. A., Nelson, R. R., \& Todd, P. A. (1992). Perceived usefulness, ease of use, and usage of information technology: A replication. MIS quarterly, 227-247.

- Beer, J., Prakash, A., Smarr, C., Chen, T., Hawkins, K., Nguyen, H., \& Rogers, W. (2017). Older users' acceptance of an assistive robot: Attitudinal changes following brief exposure. Gerontechnology, 16(1), 21-36.

- Beer, J. M., Smarr, C.-A., Chen, T. L., Prakash, A., Mitzner, T. L., Kemp, C. C., \& Rogers, W. A. (2012). The domesticated robot: design guidelines for assisting older adults to age in place. Paper presented at the Proceedings of the seventh annual ACM/IEEE international conference on Human-Robot Interaction. pp. 335-342.

- $\quad$ Begum, M., Huq, R., Wang, R., \& Mihailidis, A. (2015). Collaboration of an assistive robot and older adults with dementia. Gerontechnology, 13(4), 405-419.

- Broadbent, E., Stafford, R., \& MacDonald, B. (2009). Acceptance of Healthcare Robots for the Older Population: Review and Future Directions. International Journal of Social Robotics, 1(4), 319-330. doi:10.1007/s12369-009-0030-6

- Broadbent, E., Tamagawa, R., Patience, A., Knock, B., Kerse, N., Day, K., \& MacDonald, B. A. (2012). Attitudes towards health-care robots in a retirement village. Australasian Journal on Ageing, 31(2), 115-120. doi:10.1111/j.1741-6612.2011.00551.x

- Broekens, J., Heerink, M., \& Rosendal, H. (2009). Assistive social robots in elderly care: a review. Gerontechnology, 8(2), 94-103.

- Buddy. (2018). BUDDY-the Emotional Robot (EN/FR). Available at:https://www.youtube.com/watch?v=1Z3kws Ujrbo. [Retrieved on 24 May 2019]

- Campbell, A. (2011). Dementia care: could animal robots benefit residents? Nursing \& Residential Care, 13(12), 602-604.

- Charness, N., \& Boot, W. R. (2009). Aging and Information Technology Use: Potential and Barriers. Current Directions in Psychological Science, 18(5), 253-258. doi:10.1111/j.1467-8721.2009.01647.x 
- Chen, K., \& Chan, A. H. (2011). A review of technology acceptance by older adults. Gerontechnology, 10(1), 1-12.

- Crites Jr, S. L., Fabrigar, L. R., \& Petty, R. E. (1994). Measuring the affective and cognitive properties of attitudes: Conceptual and methodological issues. Personality and Social Psychology Bulletin, 20(6), 619-634.

- Davis, F. D. (1989). Perceived usefulness, perceived ease of use, and user acceptance of information technology. MIS quarterly, 319-340.

- Dillon, A. (2001). User acceptance of information technology. In Encyclopedia of human factors and ergonomics: London: Taylor and Francis.

- Eagly, A. H., \& Chaiken, S. (1993). The psychology of attitudes: Harcourt Brace Jovanovich College Publishers.

- $\quad$ Ezer, N., Fisk, A. D., \& Rogers, W. A. (2009). More than a servant: Self-reported willingness of younger and older adults to having a robot perform interactive and critical tasks in the home. Paper presented at the Proceedings of the human factors and ergonomics society annual meeting. pp. 136-140.

- $\quad$ Fausset, C. B., Kelly, A. J., Rogers, W. A., \& Fisk, A. D. (2011). Challenges to aging in place: Understanding home maintenance difficulties. Journal of Housing for the Elderly, 25(2), 125-141.

- $\quad$ Forlizzi, J., DiSalvo, C., \& Gemperle, F. (2004). Assistive robotics and an ecology of elders living independently in their homes. Human-Computer Interaction, 19(1), 25-59.

- Gallego-Perez, J., Lohse, M., \& Evers, V. (2013). Robots to motivate elderly people: present and future challenges. Paper presented at the 2013 IEEE RO-MAN. pp. 685-690.

- Garcia-Soler, A., Facal, D., Diaz-Orueta, U., Pigini, L., Blasi, L., \& Qiu, R. X. (2018). Inclusion of service robots in the daily lives of frail older users: A step-by-step definition procedure on users' requirements. Archives of Gerontology and Geriatrics, 74, 191-196. doi:10.1016/j.archger.2017.10.024

- Gitlin, L. N. (2003). Conducting research on home environments: Lessons learned and new directions. 43(5), 628-637.

- Gnambs, T., \& Appel, M. (2019). Are robots becoming unpopular? Changes in attitudes towards autonomous robotic systems in Europe. Computers in Human Behavior, 93, 53-61.

- Groves, M. A., \& Wilson, V. F. (1993). To move or not to move? Factors influencing the housing choice of elderly persons. Journal of Housing for the Elderly, 10(1-2), 33-47.

- Hedden, T., \& Gabrieli, J. D. E. (2004). Insights into the ageing mind: A view from cognitive neuroscience. Nature Reviews Neuroscience, 5(2), 87-96. doi:10.1038/nrn1323

- Heerink, M., Krose, B., Evers, V., \& Wielinga, B. (2006). The influence of a robot's social abilities on acceptance by elderly users. Paper presented at the ROMAN 2006-The 15th IEEE International Symposium on Robot and Human Interactive Communication. pp. 521-526.

- Heerink, M., Krose, B., Evers, V., \& Wielinga, B. (2009). Measuring acceptance of an assistive social robot: a suggested toolkit. Paper presented at the RO-MAN 2009-The 18th IEEE International Symposium on Robot and Human Interactive Communication. pp. 528-533.

- Heerink, M., Krose, B., Evers, V., \& Wielinga, B. (2010). Assessing Acceptance of Assistive Social Agent Technology by Older Adults: the Almere Model. International Journal of Social Robotics, 2(4), 361-375. doi:10.1007/s12369-010-0068-5

- Heerink, M., Kröse, B., Evers, V., \& Wielinga, B. (2008). The influence of social presence on acceptance of a companion robot by older people.

- Hoefman, R., Meulenkamp, T., \& De Jong, J. (2017). Who is responsible for providing care? Investigating the role of care tasks and past experiences in a cross-sectional survey in the Netherlands. BMC health services research, 17(1), 477.

- Jaschinski, C., \& Ben Allouch, S. (2019). Listening to the ones who care: exploring the perceptions of informal caregivers towards ambient assisted living applications. Journal of Ambient Intelligence and Humanized Computing, 10(2), 761-778. doi:10.1007/s12652-018-0856-6 
- Kelly, A. J., Fausset, C. B., Rogers, W., \& Fisk, A. D. (2014). Responding to Home Maintenance Challenge Scenarios: The Role of Selection, Optimization, and Compensation in Aging-in-Place. Journal of Applied Gerontology, 33(8), 1018-1042. doi:10.1177/0733464812456631

- Klamer, T., \& Allouch, S. B. (2010). Acceptance and use of a social robot by elderly users in a domestic environment. Paper presented at the 2010 4th International Conference on Pervasive Computing Technologies for Healthcare. pp. 1-8.

- $\quad$ Lawton, M. P. (1990). Aging and performance of home tasks. Human Factors, 32(5), 527-536.

- Louie, W.-Y. G., McColl, D., \& Nejat, G. (2014). Acceptance and attitudes toward a human-like socially assistive robot by older adults. Assistive Technology, 26(3), 140-150.

- $\quad$ Lukasik, S., Tobis, S., Wieczorowska-Tobis, K., \& Suwalska, A. (2018). Could Robots Help Older People with Age-Related Nutritional Problems? Opinions of Potential Users. International Journal of Environmental Research and Public Health, 15(11), 2535. doi:10.3390/ijerph15112535

- Melenhorst, A. S., Rogers, W. A., \& Bouwhuis, D. G. (2006). Older adults' motivated choice for technological innovation: Evidence for benefit-driven selectivity. Psychology and Aging, 21(1), 190-195. doi:10.1037/0882-7974.21.1.190

- $\quad$ Mitzner, T. L., Chen, T. L., Kemp, C. C., \& Rogers, W. A. (2014). Identifying the Potential for Robotics to Assist Older Adults in Different Living Environments. International Journal of Social Robotics, 6(2), 213-227. doi:10.1007/s12369-013-0218-7

- Moro, C., Lin, S., Nejat, G., \& Mihailidis, A. (2019). Social Robots and Seniors: A Comparative Study on the Influence of Dynamic Social Features on Human-Robot Interaction. International Journal of Social Robotics, $\quad 11(1), \quad 5-24$. doi:10.1007/s12369-018-0488-1

- $\quad$ Nomura, T., Kanda, T., Suzuki, T., \& Kato, K. (2008). Prediction of human behavior in human--robot interaction using psychological scales for anxiety and negative attitudes toward robots. IEEE transactions on robotics, 24(2),
$442-451$.

- $\quad$ Rantanen, T., Lehto, P., Vuorinen, P., \& Coco, K. (2018). The adoption of care robots in home care-A survey on the attitudes of Finnish home care personnel. Journal of clinical nursing, 27(9-10), 1846-1859.

- $\quad$ Robinson, H., MacDonald, B., \& Broadbent, E. (2014). The Role of Healthcare Robots for Older People at Home: A Review. International Journal of Social Robotics, 6(4), 575-591. doi:10.1007/s12369-014-0242-2

- $\quad$ Rogers, W. A., Meyer, B., Walker, N., \& Fisk, A D. (1998). Functional limitations to daily living tasks in the aged: A focus group analysis. Human Factors, 40(1), 111-125. doi:10.1518/001872098779480613

- Santos, J. R. A. (1999). Cronbach's alpha: A tool for assessing the reliability of scales. Journal of extension, 37(2), 1-5.

- Smarr, C.-A., Prakash, A., Beer, J. M., Mitzner, T. L., Kemp, C. C., \& Rogers, W. A. (2012). Older adults 'preferences for and acceptance of robot assistance for everyday living tasks. Paper presented at the Proceedings of the human factors and ergonomics society annual meeting. pp. 153-157.

- Smarr, C. A., Mitzner, T. L., Beer, J. M., Prakash, A., Chen, T. L., Kemp, C. C., \& Rogers, W. A. (2014). Domestic Robots for Older Adults: Attitudes, Preferences, and Potential. International Journal of Social Robotics, 6(2), 229-247. doi:10.1007/s12369-013-0220-0

- Stafford, R. Q., MacDonald, B. A., Jayawardena, C., Wegner, D. M., \& Broadbent, E. (2014). Does the robot have a mind? Mind perception and attitudes towards robots predict use of an eldercare robot. International Journal of Social Robotics, 6(1), 17-32.

- Takayama, L., Ju, W., \& Nass, C. (2008). Beyond dirty, dangerous and dull: what everyday people think robots should do. Paper presented at the 2008 3rd ACM/IEEE International Conference on Human-Robot Interaction (HRI). pp. 25-32.

- United Nations. (2017). World Population Ageing 2017. Available at: https://www.un.org/en/development/desa/popul 
ation/publications/pdf/ageing/WPA2017_Highl ights.pdf. [Retrieved on 29 May 2019].

- United Nations Department of Economic and Social Affairs. (2007). World Population Ageing 2007. Available at: https://www.un.org/en/development/desa/popul ation/publications/pdf/ageing/WorldPopulation AgeingReport2007.pdf. [Retrieved on 26 July 2019].

- United Nations Department of Economic and Social Affairs. (2015). World population prospects: the 2015 revision. Available at: https://esa.un.org/unpd/wpp/publications/files/ key_findings_wpp_2015.pdf . [Retrieved on 25 June 2019].

- United Nations Department of Economic and Social Affairs (UN DESA). (2013). World population prospects: the 2012 revision. Volume II: demographic profiles. Available at: https://esa.un.org/unpd/wpp/publications/Files/ WPP2012_Volume-II-Demographic-Profiles.p df. [Retrieved on 10 July 2019]

- Venkatesh, V., Morris, M. G., Davis, G. B., \& Davis, F. D. (2003). User acceptance of information technology: Toward a unified view. MIS quarterly, 425-478.

- $\quad$ Wang, R. H., Sudhama, A., Begum, M., Huq, R., \& Mihailidis, A. (2017). Robots to assist daily activities: views of older adults with Alzheimer's disease and their caregivers. International Psychogeriatrics, 29(1), 67-79.

- Whelan, S., Murphy, K., Barrett, E., Krusche, C., Santorelli, A., \& Casey, D. (2018). Factors Affecting the Acceptability of Social Robots by Older Adults Including People with Dementia or Cognitive Impairment: A Literature Review. International Journal of Social Robotics, 10(5), 643-668. doi:10.1007/s12369-018-0471-x
- Wu, Y. H., Fassert, C., \& Rigaud, A. S. (2012). Designing robots for the elderly: Appearance issue and beyond. Archives of Gerontology and Geriatrics, $\quad$ 54(1), 121-126. doi:10.1016/j.archger.2011.02.003

- $\quad$ Xu, Q. L., Ng, J. S. L., Tan, O. Y., \& Huang, Z. Y. (2015). Needs and attitudes of Singaporeans towards home service robots: a multi-generational perspective. Universal Access in the Information Society, 14(4), 477-486. doi:10.1007/s10209-014-0355-2

- Yang, H.-d., \& Yoo, Y. (2004). It's all about attitude: revisiting the technology acceptance model. Decision Support Systems, 38(1), 19-31.

- Young, J. E., Hawkins, R., Sharlin, E., \& Igarashi, T. (2009). Toward Acceptable Domestic Robots: Applying Insights from Social Psychology. International Journal of Social Robotics, 1(1), 95-108. doi:10.1007/s12369-008-0006-y

- Zsiga, K., Edelmayer, G., Rumeau, P., Peter, O., Toth, A., \& Fazekas, G. (2013). Home care robot for socially supporting the elderly: focus group studies in three European countries to screen user attitudes and requirements. International Journal of Rehabilitation Research, 36(4), 375-378. doi:10.1097/MRR.0b013e3283643d26

- Zsiga, K., Toth, A., Pilissy, T., Peter, O., Denes, Z., \& Fazekas, G. (2018). Evaluation of a companion robot based on field tests with single older adults in their homes. Assistive Technology, 30(5), 259-266. doi:10.1080/10400435.2017.13221. 


\section{TABLES}

Table-1: Scores of Items in Robot Assistance Attitude Questionnaire for today's seniors and future seniors

\begin{tabular}{|c|c|c|c|c|c|c|c|c|c|c|}
\hline Code & Items & Sample & $n$ & $M$ & $S D$ & Min & $\begin{array}{c}M a \\
x\end{array}$ & $U$ & $Z$ & $p$-Value* \\
\hline \multirow{12}{*}{ PEOU } & \multirow{2}{*}{$\begin{array}{l}\text { I think the use of robots } \\
\text { is clear and } \\
\text { understandable }\end{array}$} & Seniors & 29 & 3.62 & 0.622 & 2 & 5 & \multirow[t]{2}{*}{365.500} & \multirow[t]{2}{*}{-0.953} & \multirow[t]{2}{*}{0.341} \\
\hline & & future seniors & 29 & 3.83 & 0.711 & 3 & 5 & & & \\
\hline & \multirow{2}{*}{$\begin{array}{l}\text { It is easy to learn how } \\
\text { to use a robot }\end{array}$} & Seniors & 29 & 3.07 & 0.753 & 1 & 4 & \multirow[t]{2}{*}{196.000} & \multirow[t]{2}{*}{-3.742} & \multirow[t]{2}{*}{0.000} \\
\hline & & future seniors & 29 & 3.93 & 0.753 & 3 & 5 & & & \\
\hline & \multirow{2}{*}{$\begin{array}{l}\text { I find it controllable to } \\
\text { get the robot for } \\
\text { assistance }\end{array}$} & Seniors & 29 & 3.69 & 0.471 & 3 & 4 & \multirow[t]{2}{*}{396.000} & \multirow[t]{2}{*}{-0.474} & \multirow[t]{2}{*}{0.636} \\
\hline & & future seniors & 29 & 3.76 & 0.511 & 3 & 5 & & & \\
\hline & \multirow{2}{*}{$\begin{array}{l}\text { Using the robot for } \\
\text { assistance is very } \\
\text { flexible }\end{array}$} & Seniors & 29 & 3.79 & 0.412 & 3 & 4 & \multirow[t]{2}{*}{356.000} & \multirow[t]{2}{*}{-1.118} & \multirow[t]{2}{*}{0.264} \\
\hline & & future seniors & 29 & 3.66 & 0.857 & 2 & 5 & & & \\
\hline & \multirow{2}{*}{$\begin{array}{l}\text { I find it easy to use the } \\
\text { robot }\end{array}$} & Seniors & 29 & 3.48 & 0.634 & 2 & 5 & \multirow[t]{2}{*}{372.500} & \multirow[t]{2}{*}{-0.842} & \multirow[t]{2}{*}{0.400} \\
\hline & & future seniors & 29 & 3.62 & 0.561 & 3 & 5 & & & \\
\hline & \multirow{2}{*}{$\begin{array}{l}\text { It is easy for me to } \\
\text { become skillful in } \\
\text { operating the robot }\end{array}$} & Seniors & 29 & 3.21 & 0.774 & 2 & 4 & \multirow[t]{2}{*}{235.000} & \multirow[t]{2}{*}{-3.052} & \multirow[t]{2}{*}{0.002} \\
\hline & & future seniors & 29 & 3.97 & 0.823 & 3 & 5 & & & \\
\hline \multirow{6}{*}{ ATT } & \multirow{2}{*}{$\begin{array}{l}\text { I think it's a good idea } \\
\text { to use the robot in my } \\
\text { daily life }\end{array}$} & Seniors & 29 & 3.93 & 0.258 & 3 & 4 & \multirow[t]{2}{*}{342.500} & \multirow[t]{2}{*}{-1.620} & \multirow[t]{2}{*}{0.105} \\
\hline & & future seniors & 29 & 4.10 & 0.724 & 2 & 5 & & & \\
\hline & \multirow{2}{*}{$\begin{array}{l}\text { The robot assistance in } \\
\text { ADLs would make my } \\
\text { life more interesting }\end{array}$} & Seniors & 29 & 4.07 & 0.651 & 3 & 5 & 393.000 & -0.508 & 0.612 \\
\hline & & future seniors & 29 & 3.97 & 0.458 & 2 & 5 & & & \\
\hline & It's good to make use of & Seniors & 29 & 4.14 & 0.516 & 3 & 5 & 350.500 & -1.258 & 0.208 \\
\hline & $\begin{array}{l}\text { the robot in my daily } \\
\text { life }\end{array}$ & future seniors & 29 & 3.90 & 0.772 & 2 & 5 & & & \\
\hline & Using robot assistance & Seniors & 29 & 3.97 & 0.325 & 3 & 5 & 326.500 & -1.908 & 0.056 \\
\hline & $\begin{array}{l}\text { helps me work more } \\
\text { quickly }\end{array}$ & future seniors & 29 & 4.21 & 0.620 & 3 & 5 & & & \\
\hline & Using robot assistance & Seniors & 29 & 4.21 & 0.491 & 3 & 5 & 367.500 & -1.105 & 0.269 \\
\hline & makes my job easier & future seniors & 29 & 4.07 & 0.458 & 3 & 5 & & & \\
\hline & Using robot assistance & Seniors & 29 & 3.86 & 0.639 & 2 & 5 & 357.000 & -1.233 & 0.218 \\
\hline PU & $\begin{array}{l}\text { enhances my } \\
\text { effectiveness }\end{array}$ & future seniors & 29 & 4.07 & 0.530 & 3 & 5 & & & \\
\hline & Using robot assistance & Seniors & 29 & 3.97 & 0.499 & 3 & 5 & 383.500 & -0.694 & 0.488 \\
\hline
\end{tabular}




\begin{tabular}{|c|c|c|c|c|c|c|c|c|c|}
\hline $\begin{array}{l}\text { can increase my } \\
\text { productivity in daily life }\end{array}$ & future seniors & 29 & 4.07 & 0.651 & 3 & 5 & & & \\
\hline \multirow{2}{*}{$\begin{array}{l}\text { Using robot assist helps } \\
\text { with my job } \\
\text { performance }\end{array}$} & Seniors & 29 & 4.03 & 0.499 & 3 & 5 & \multirow[t]{2}{*}{394.000} & \multirow[t]{2}{*}{-0.506} & \multirow[t]{2}{*}{0.613} \\
\hline & future seniors & 29 & 4.10 & 0.618 & 3 & 5 & & & \\
\hline \multirow{2}{*}{$\begin{array}{l}\text { It is useful to have robot } \\
\text { assistance in my daily } \\
\text { life }\end{array}$} & Seniors & 29 & 4.10 & 0.489 & 3 & 5 & \multirow[t]{2}{*}{405.500} & \multirow[t]{2}{*}{-0.292} & \multirow[t]{2}{*}{0.770} \\
\hline & future seniors & 29 & 4.14 & 0.581 & 3 & 5 & & & \\
\hline
\end{tabular}

Abbreviation: SD, standard deviation. M, Mean. Min, Minimum. Max, Maximum. Mdn, Median.

Table 2 Acceptance of Use of Robot Assistance in ADLs: Comparison between today's seniors and future seniors

\begin{tabular}{|c|c|c|c|c|c|c|c|c|c|c|}
\hline Items & Sample & $n$ & $M$ & $S D$ & Min & $\operatorname{Max}$ & $M d n$ & $U$ & $Z$ & $p$-Value* \\
\hline \multirow{2}{*}{$\begin{array}{l}\text { Preparing } \\
\text { breakfast }\end{array}$} & Seniors & 29 & 3.41 & 0.733 & 2 & 4 & 4.00 & \multirow[t]{2}{*}{239.000} & \multirow[t]{2}{*}{-3.042} & \multirow[t]{2}{*}{0.002} \\
\hline & future seniors & 29 & 4.03 & 1.052 & 2 & 5 & 4.00 & & & \\
\hline \multirow[t]{2}{*}{ Watching TV } & Seniors & 29 & 3.31 & 0.850 & 2 & 5 & 3.00 & \multirow[t]{2}{*}{344.000} & \multirow[t]{2}{*}{-1.271} & \multirow[t]{2}{*}{0.204} \\
\hline & future seniors & 29 & 3.62 & 0.862 & 2 & 5 & 4.00 & & & \\
\hline \multirow[t]{2}{*}{ Karaoke } & Seniors & 29 & 3.48 & 0.738 & 2 & 5 & 4.00 & \multirow[t]{2}{*}{356.000} & \multirow[t]{2}{*}{-1.128} & \multirow[t]{2}{*}{0.259} \\
\hline & future seniors & 29 & 3.69 & 0.712 & 2 & 5 & 4.00 & & & \\
\hline \multirow{2}{*}{$\begin{array}{l}\text { Grocery } \\
\text { shopping }\end{array}$} & Seniors & 29 & 3.45 & 0.572 & 2 & 4 & 3.00 & \multirow[t]{2}{*}{402.500} & \multirow[t]{2}{*}{-0.295} & \multirow[t]{2}{*}{0.768} \\
\hline & future seniors & 29 & 3.38 & 1.147 & 2 & 5 & 3.00 & & & \\
\hline \multirow{2}{*}{$\begin{array}{l}\text { Friends } \\
\text { get-together }\end{array}$} & Seniors & 29 & 3.24 & 0.786 & 2 & 4 & 3.00 & \multirow[t]{2}{*}{403.500} & \multirow[t]{2}{*}{-0.280} & \multirow[t]{2}{*}{0.780} \\
\hline & future seniors & 29 & 3.28 & 1.099 & 1 & 5 & 3.00 & & & \\
\hline \multirow[t]{2}{*}{ Eating } & Seniors & 29 & 3.28 & 0.797 & 2 & 5 & 3.00 & \multirow{2}{*}{359.000} & \multirow{2}{*}{-1.003} & \multirow{2}{*}{0.316} \\
\hline & future seniors & 29 & 3.00 & 1.102 & 1 & 5 & 3.00 & & & \\
\hline \multirow{2}{*}{$\begin{array}{l}\text { Using social } \\
\text { software }\end{array}$} & Seniors & 29 & 3.62 & 0.677 & 2 & 5 & 4.00 & \multirow[t]{2}{*}{350.000} & \multirow[t]{2}{*}{-1.233} & \multirow[t]{2}{*}{0.218} \\
\hline & future seniors & 29 & 3.76 & 1.057 & 1 & 5 & 4.00 & & & \\
\hline \multirow[t]{2}{*}{ Using phones } & Seniors & 29 & 3.72 & 0.528 & 3 & 5 & 4.00 & 386.000 & -0.638 & 0.523 \\
\hline & future seniors & 29 & 3.76 & 0.786 & 2 & 5 & 4.00 & & & \\
\hline Walking & Seniors & 29 & 3.69 & 0.660 & 2 & 5 & 4.00 & 278.500 & -2.374 & 0.018 \\
\hline & future seniors & 29 & 3.21 & 0.940 & 2 & 5 & 3.00 & & & \\
\hline Bathing & Seniors & 29 & 2.90 & 1.012 & 1 & 5 & 3.00 & 300.000 & -1.967 & 0.049 \\
\hline & future seniors & 29 & 2.38 & 0.862 & 1 & 4 & 2.00 & & & \\
\hline Using computer & Seniors & 29 & 3.93 & 0.458 & 3 & 5 & 4.00 & 267.500 & -2.928 & 0.003 \\
\hline & future seniors & 29 & 4.34 & 0.553 & 3 & 5 & 4.00 & & & \\
\hline Reminding to & Seniors & 29 & 4.07 & 0.371 & 3 & 5 & 4.00 & 253.000 & -3.138 & 0.002 \\
\hline carry items & future seniors & 29 & 4.45 & 0.686 & 2 & 5 & 5.00 & & & \\
\hline Reminding to & Seniors & 29 & 4.07 & 0.371 & 3 & 5 & 4.00 & 225.500 & -3.667 & 0.000 \\
\hline take medicine & future seniors & 29 & 4.55 & 0.506 & 4 & 5 & 5.00 & & & \\
\hline Dancing & Seniors & 29 & 3.48 & 0.634 & 2 & 4 & 4.00 & 391.500 & -0.488 & 0.626 \\
\hline & future seniors & 29 & 3.38 & 0.942 & 2 & 5 & 3.00 & & & \\
\hline
\end{tabular}




\begin{tabular}{|c|c|c|c|c|c|c|c|c|c|c|}
\hline \multirow[t]{2}{*}{ Emergency call } & Seniors & 29 & 4.00 & 0.463 & 3 & 5 & 4.00 & \multirow[t]{2}{*}{147.500} & \multirow[t]{2}{*}{-4.818} & \multirow[t]{2}{*}{0.000} \\
\hline & future seniors & 29 & 4.72 & 0.455 & 4 & 5 & 5.00 & & & \\
\hline \multirow[t]{2}{*}{ Playing Tai Chi } & Seniors & 29 & 3.62 & 0.622 & 2 & 5 & 4.00 & \multirow[t]{2}{*}{303.500} & \multirow[t]{2}{*}{-1.990} & \multirow[t]{2}{*}{0.047} \\
\hline & future seniors & 29 & 3.21 & 0.861 & 1 & 5 & 3.00 & & & \\
\hline \multirow{2}{*}{$\begin{array}{l}\text { Reminding } \\
\text { where things are }\end{array}$} & Seniors & 29 & 4.07 & 0.258 & 4 & 5 & 4.00 & \multirow[t]{2}{*}{216.500} & \multirow[t]{2}{*}{-3.836} & \multirow[t]{2}{*}{0.000} \\
\hline & future seniors & 29 & 4.55 & 0.572 & 3 & 5 & 5.00 & & & \\
\hline \multirow{2}{*}{$\begin{array}{l}\text { Playing } \\
\text { Mahjong }\end{array}$} & Seniors & 29 & 3.31 & 0.806 & 2 & 5 & 3.00 & \multirow[t]{2}{*}{339.000} & \multirow[t]{2}{*}{-1.348} & \multirow[t]{2}{*}{0.178} \\
\hline & future seniors & 29 & 2.97 & 0.906 & 1 & 4 & 3.00 & & & \\
\hline \multirow[t]{2}{*}{ Cleaning } & Seniors & 29 & 4.07 & 0.371 & 3 & 5 & 4.00 & \multirow[t]{2}{*}{266.500} & \multirow[t]{2}{*}{-2.924} & \multirow[t]{2}{*}{0.003} \\
\hline & future seniors & 29 & 4.45 & 0.572 & 3 & 5 & 4.00 & & & \\
\hline \multirow{2}{*}{$\begin{array}{l}\text { Reminder of } \\
\text { important things }\end{array}$} & Seniors & 29 & 4.14 & 0.351 & 4 & 5 & 4.00 & \multirow[t]{2}{*}{174.000} & \multirow[t]{2}{*}{-4.468} & \multirow[t]{2}{*}{0.000} \\
\hline & future seniors & 29 & 4.72 & 0.455 & 4 & 5 & 5.00 & & & \\
\hline \multirow[t]{2}{*}{ Walking stairs } & Seniors & 29 & 3.69 & 0.541 & 3 & 5 & 4.00 & \multirow[t]{2}{*}{402.000} & -0.316 & 0.752 \\
\hline & future seniors & 29 & 3.72 & 0.922 & 2 & 5 & 4.00 & & & \\
\hline Preparing & Seniors & 29 & 3.90 & 0.618 & 2 & 5 & 4.00 & 348.500 & -1.293 & 0.196 \\
\hline lessons & future seniors & 29 & 4.10 & 0.772 & 2 & 5 & 4.00 & & & \\
\hline Looking for & Seniors & 29 & 4.14 & 0.441 & 3 & 5 & 4.00 & 240.500 & -3.286 & 0.001 \\
\hline things & future seniors & 29 & 4.59 & 0.501 & 4 & 5 & 5.00 & & & \\
\hline Washing and & Seniors & 29 & 3.97 & 0.499 & 3 & 5 & 4.00 & 338.000 & -1.438 & 0.150 \\
\hline drying beddings & future seniors & 29 & 4.14 & 0.915 & 2 & 5 & 4.00 & & & \\
\hline Cooking & Seniors & 29 & 3.90 & 0.557 & 2 & 5 & 4.00 & 410.000 & -0.188 & 0.851 \\
\hline & future seniors & 29 & 3.76 & 1.023 & 2 & 5 & 4.00 & & & \\
\hline Inspection and & Seniors & 29 & 3.97 & 0.566 & 3 & 5 & 4.00 & 250.000 & -3.092 & 0.002 \\
\hline $\begin{array}{l}\text { maintenance of } \\
\text { home appliances }\end{array}$ & future seniors & 29 & 4.45 & 0.506 & 4 & 5 & 4.00 & & & \\
\hline Assisting & Seniors & 29 & 3.90 & 0.618 & 2 & 5 & 4.00 & 398.000 & -0.395 & 0.693 \\
\hline movements & future seniors & 29 & 3.97 & 0.823 & 2 & 5 & 4.00 & & & \\
\hline Shopping & Seniors & 29 & 3.62 & 0.622 & 2 & 5 & 4.00 & 354.000 & -1.120 & 0.263 \\
\hline & future seniors & 29 & 3.31 & 1.039 & 2 & 5 & 4.00 & & & \\
\hline Laundry & Seniors & 29 & 3.90 & 0.489 & 3 & 5 & 4.00 & 352.000 & -1.305 & 0.192 \\
\hline & future seniors & 29 & 4.03 & 0.778 & 2 & 5 & 4.00 & & & \\
\hline Drying clothes & Seniors & 29 & 3.90 & 0.557 & 3 & 5 & 4.00 & 344.500 & -1.349 & 0.177 \\
\hline & future seniors & 29 & 4.07 & 0.842 & 2 & 5 & 4.00 & & & \\
\hline Chopping & Seniors & 29 & 3.59 & 0.682 & 2 & 5 & 4.00 & 392.000 & -0.479 & 0.632 \\
\hline vegetables & future seniors & 29 & 3.66 & 1.010 & 2 & 5 & 4.00 & & & \\
\hline Photo archiving & Seniors & 29 & 3.97 & 0.499 & 3 & 5 & 4.00 & 257.000 & -2.928 & 0.003 \\
\hline & future seniors & 29 & 4.41 & 0.628 & 3 & 5 & 4.00 & & & \\
\hline
\end{tabular}

Abbreviation: SD, standard deviation. M, Mean. Min, Minimum. Max, Maximum. 